Received July 23, 2018

Revised 1st, August 28, 2018 2nd, September 3, 2018 Accepted September 4, 2018

\section{Corresponding author}

Seongtae Jeong, M.D., Ph.D.

Department of Anesthesiology and

Pain Medicine, Chonnam National

University Medical School and

Hospital, 42 Jebong-ro, Dong-gu,

Gwangju 61469, Korea

Tel: 82-62-220-6895

Fax: 82-62-232-6294

E-mail: anesjst@jnu.ac.kr

ORCID

https://orcid.org/0000-0002-6245-9779

\title{
Effect of a combination of $2 \%$ lidocaine jelly and thermally softened endotracheal tube on postoperative sore throat
}

\section{Ji-A Song, Seongheon Lee, Jeong-ll Choi, Hyung Gon Lee, Sue Youn Park, Jeong Yeon Hwang, Sanghee Park, and Seongtae Jeong}

Department of Anesthesiology and Pain Medicine, Chonnam National University Medical School and Hospital, Gwangju, Korea

Background: Postoperative sore throat (POST) is a common adverse event after general anesthesia. The aim of this study was to evaluate the effectiveness of $2 \%$ lidocaine jelly applied on the single-lumen endotracheal tube (ETT) and thermal softening of the ETT, and a combination of both interventions on the development of POST.

Methods: Patients $(n=144)$ undergoing general anesthesia were randomly assigned to one of four groups: Control group (un-softened ETT lubricated with saline); Lidocaine group (un-softened ETT lubricated with $2 \%$ lidocaine jelly); Softened group (thermally softened ETT lubricated with saline); and Combined group (thermally softened ETT lubricated with $2 \%$ lidocaine jelly). Sore throat was evaluated at $0,1,6,24$, and $48 \mathrm{~h}$ after extubation. The occurrence of any postoperative complication was also assessed including hoarseness and coughing.

Results: No significant difference was observed in the severity of POST at all time points. However, the incidences of POST for overall $(0-48 \mathrm{~h})$ and the immediately following period $(0 \mathrm{~h})$ were significantly lower in the Combined group (52.9\% and $47.1 \%)$ than in the Control group (79.4\% and 76.5\%), Lidocaine group (81.8\% and 78.8\%), and Softened group (82.9\% and $74.3 \%$ ). The overall incidence of hoarseness did not differ among the groups. No other postoperative complication was observed in any of the patients.

Conclusions: No differences were observed in the severity of POST. However, $2 \%$ lidocaine jelly applied on thermally softened ETT reduced the overall incidence of POST. Therefore, this combined intervention could be considered as an alleviating strategy for POST.

Keywords: Endotracheal tube; Sore throat; Thermal softening; $2 \%$ lidocaine jelly.

\section{INTRODUCTION}

Postoperative sore throat (POST) is a common adverse event after surgery under general anesthesia requiring tracheal intubation; its incidence ranges from $14 \%$ to $54 \%$ [1-4]. Since most associated symptoms resolve spontaneously without treatment, anesthesiologists have historically not focused on finding a way to prevent and treat POST. However, POST could adversely affect patient satisfaction and activity after hospital discharge $[4,5]$. Therefore, for the quality of anesthesia care, POST needs to be actively prevented.

Lidocaine, a pharmacological intervention, has often been

This is an Open Access article distributed under the terms of the Creative Commons Attribution Non-Commercial License (http://creativecommons.org/licenses/by-nc/4.0) which permits unrestricted non-commercial use, distribution, and reproduction in any medium, provided the original work is properly cited. 
used for the prevention of POST in common clinical practice. While a recent systematic review showed this practice to be generally beneficial, the outcome appears to vary according to the route of administration [6]. Especially, lidocaine jelly applied on the endotracheal tube (ETT) was believed to be beneficial due to the lubricating and local anesthetic effects, although its effectiveness for the prevention of POST remains controversial [7-9].

Various non-pharmacological interventions, such as the change of tube size or cuff design, have also been investigated to prevent POST. Recently, Seo et al. [10] showed that the incidence of POST and vocal cord injuries with doublelumen endobronchial tube decreased by thermal softening of the tube, which is an established method used to decrease trauma to the nasal passages during nasotracheal intubation [11]. This non-pharmacological intervention has seldom been studied for the prevention of POST, particularly in orotracheal intubation with single-lumen ETT.

We hypothesized that a combination of these pharmacological and non-pharmacological interventions may be more effective for the alleviation of POST than either intervention alone. The primary objective of this trial was to determine whether this combined treatment could reduce the severity of POST. The secondary objective was to assess the incidence of sore throat and hoarseness.

\section{MATERIALS AND METHODS}

This prospective, randomized controlled trial was approved by our Institutional Review Board (CNUH 2016-244) and registered at the Clinical Research Information Service (http://cris.nih.go.kr, KCT000216). We obtained written informed consents from all patients aged 20-70 yr who were classified as American Society of Anesthesiologists as physical status I-III scheduled for elective laparoscopic cholecystectomy or laparoscopic ovarian cystectomy. A Mallampati test was performed after patient enrolment. Based on our exclusion criteria, we excluded patients with: 1) anticipated difficult intubation (Mallampati class $\geq 3$ ); 2) previous throat pain or a hoarseness history; 3 ) a recent history of upper respiratory infection; 4) a habit of smoking; 5) cervical spine disease; and 6) a history of lidocaine allergy. Patients who re-

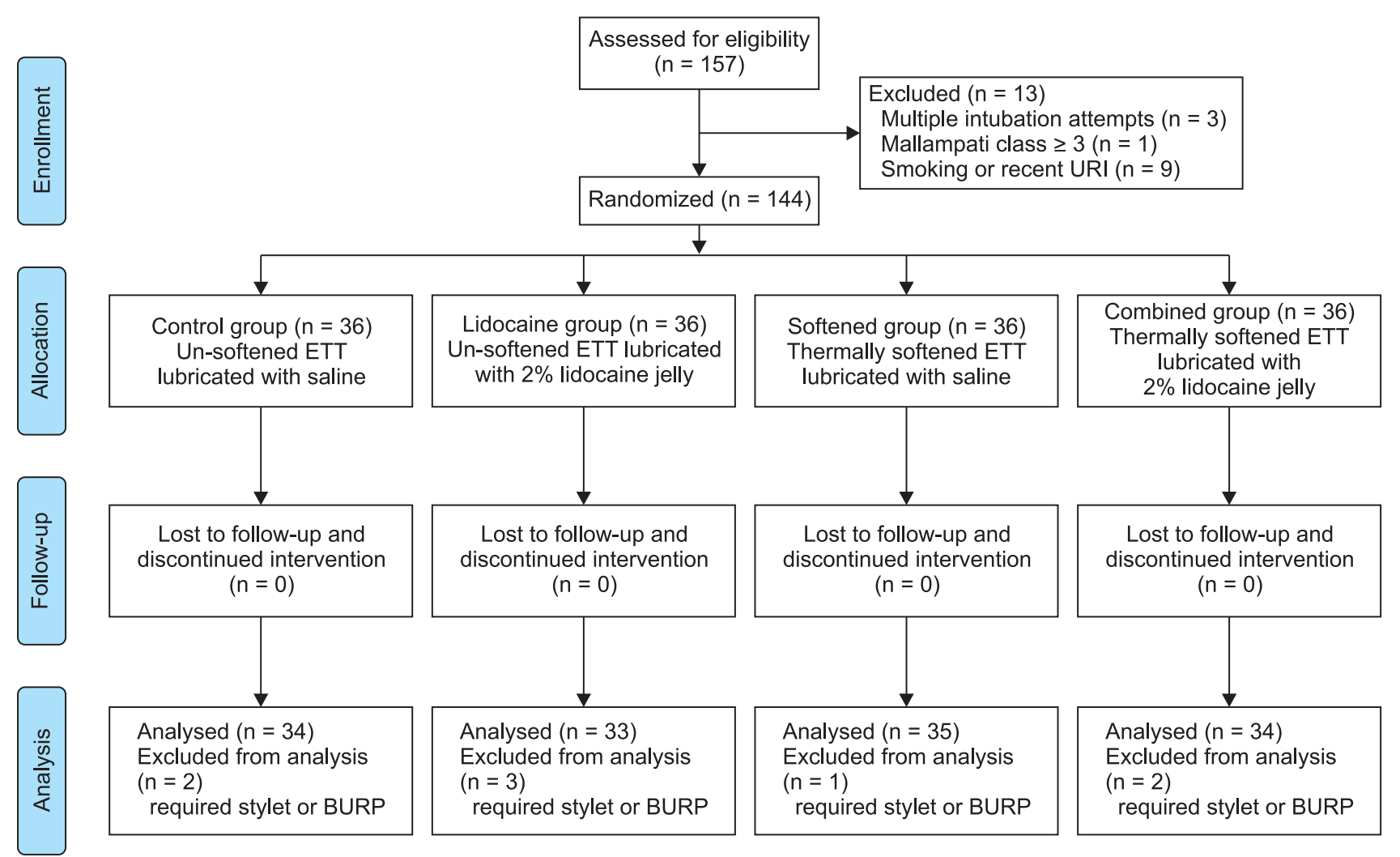

Fig. 1. Consort flow study diagram. ETT: endotracheal tube, URI: upper respiratory infection history, BURP: backward upward rightward pressure. 
quired repetitive attempts, a stylet, or the backward upward rightward pressure (BURP) maneuver at intubation were also excluded during the analysis process.

From September 2016 to February 2017, 157 patients were screened, of which 13 were excluded according to the above exclusion criteria. A total of 144 patients were allocated to 4 groups (36 patients for each group). Eight patients were excluded in the analysis process because of the use of BURP maneuver during intubation. In all other patients, the trachea was intubated without difficulty and with no patient movement. Thus, 136 patients in total were included for data analysis (Fig. 1). The demographic characteristics of the four groups were comparable (Table 1), and the variables associated with intubation did not differ among the groups (Table 2).

All patients were randomly assigned to one of the four groups: Control group (un-softened ETT lubricated with saline); Lidocaine group (un-softened ETT lubricated with $2 \%$ lidocaine jelly); Softened group (thermally softened ETT lubricated with saline); and Combined group (thermally softened ETT lubricated with $2 \%$ lidocaine jelly). According to the allocated group, all ETTs (TaperGuard ${ }^{\mathrm{TM}}$, Covidien, Ireland) were pretreated by an independent assistant. After deflating a cuff, a distal half portion of ETT was soaked in ster- ile normal saline (at $40^{\circ} \mathrm{C}$ for thermally softened ETT groups and at room temperature for un-softened ETT groups) for 5 min before tracheal intubation. Maintaining the ETTs at $40^{\circ} \mathrm{C}$ for 5 min sufficiently softened the tube and the softness was well maintained until the endotracheal intubation. The ETT was lubricated with $2 \%$ lidocaine jelly (Korea Pharma, Korea) or saline from the distal margin of the cuff to $2 \mathrm{~cm}$ above the proximal margin of the cuff $1 \mathrm{~min}$ before tracheal intubation. Allocation to each study group was randomized according to a pre-assembled list randomly generated using the Excel program. All patients were kept blinded to the group to which they were assigned. General anesthesia was induced by propofol and remifentanil with routine monitoring, and rocuronium $0.8 \mathrm{mg} / \mathrm{kg}$ was administered subsequently. Intravenous lidocaine was not injected to rule out the impact on results.

Tracheal intubation was performed with pretreated ETT (8 $\mathrm{mm}$ internal diameter for men, $7 \mathrm{~mm}$ for women) using a Macintosh laryngoscope. The cuff of the ETT was inflated with air, and the intracuff pressure was immediately adjusted to 20 to $25 \mathrm{cmH}_{2} \mathrm{O}$ using a manometer (VBM, Germany). Laryngoscopy grade (Cormack-Lehane grade), endotracheal tube cuff pressure, and duration of intubation were recorded

Table 1. Patients Characteristics

\begin{tabular}{lcccc}
\hline \multicolumn{1}{c}{ Variable } & Control $(\mathrm{n}=34)$ & Lidocaine $(\mathrm{n}=33)$ & Softened $(\mathrm{n}=35)$ & Combined $(\mathrm{n}=34)$ \\
\hline Sex $(\mathrm{M} / \mathrm{F})$ & $12 / 22$ & $11 / 22$ & $10 / 25$ & $8 / 26$ \\
Age $(\mathrm{yr})$ & $44 \pm 13$ & $43 \pm 14$ & $47 \pm 12$ & $46 \pm 12$ \\
Weight $(\mathrm{kg})$ & $62 \pm 8$ & $62 \pm 12$ & $63 \pm 11$ & $63 \pm 9$ \\
Height $(\mathrm{cm})$ & $163 \pm 7$ & $162 \pm 7$ & $162 \pm 7$ & $161 \pm 7$ \\
BMI $\left(\mathrm{kg} / \mathrm{m}^{2}\right)$ & $23 \pm 3$ & $23 \pm 4$ & $24 \pm 3$ & $24 \pm 3$ \\
ASA physical status $(\mathrm{I} / \mathrm{II} / \mathrm{III})$ & $16 / 12 / 6$ & $16 / 9 / 8$ & $15 / 12 / 8$ & $14 / 12 / 8$ \\
Remifentanil dosage $(\mu \mathrm{g} / \mathrm{kg} / \mathrm{min})$ & $0.044(0.036,0.052)$ & $0.044(0.035,0.054)$ & $0.039(0.035,0.052)$ & $0.043(0.037,0.050)$ \\
\hline
\end{tabular}

Values are presented as number of patients, mean \pm SD, or median (1Q, 3Q). Control: un-softened endotracheal tube (ETT) lubricated with saline, Lidocaine: un-softened ETT lubricated with $2 \%$ lidocaine jelly, Softened: thermally softened ETT lubricated with saline, Combined: thermally softened ETT lubricated with $2 \%$ lidocaine jelly. BMI: body mass index, ASA: American Society of Anesthesiologists.

Table 2. Variables Associated with Tracheal Intubation

\begin{tabular}{lccccc}
\hline \multicolumn{1}{c}{ Variable } & Control $(\mathrm{n}=34)$ & Lidocaine $(\mathrm{n}=33)$ & Softened $(\mathrm{n}=35)$ & Combined $(\mathrm{n}=34)$ & $\mathrm{P}$ value \\
\hline Mallampati class $(\mathrm{I} / \mathrm{II})$ & $24 / 10$ & $24 / 9$ & $24 / 11$ & $23 / 11$ & 0.970 \\
Cormack-Lehane grade $(\mathrm{I} / \mathrm{II})$ & $29 / 5$ & $28 / 5$ & $27 / 8$ & 0.774 \\
Duration of intubation $(\mathrm{min})$ & $70(60,100)$ & $70(50,97)$ & $70(55,90)$ & $75(60,98)$ & 0.632 \\
Tube cuff pressure $\left(\mathrm{cmH}_{2} \mathrm{O}\right)$ & $22(22,23)$ & $22(22,23)$ & $22(22,22)$ & $22(22,23)$ & 0.876 \\
\hline
\end{tabular}

Values are presented as number of patients or median (1Q, 3Q). Control: un-softened endotracheal tube (ETT) lubricated with saline, Lidocaine: unsoftened ETT lubricated with $2 \%$ lidocaine jelly, Softened: thermally softened ETT lubricated with saline, Combined: thermally softened ETT lubricated with $2 \%$ lidocaine jelly. 
by an independent assistant. Desflurane or sevoflurane was used for the maintenance of anesthesia with remifentanil $0.05-0.1 \mu \mathrm{g} / \mathrm{kg} / \mathrm{min}$. At the end of surgery, remifentanil infusion was stopped, and residual neuromuscular blockade was antagonized by pyridostigmine and glycopyrrolate. When the patient was fully awake, the cuff of the ETT was fully deflated and the ETT was removed smoothly.

Upon arrival in the recovery room (time $0 \mathrm{~h}$ ), another investigator, who was blinded to the group allocation, assessed the incidence of POST using a direct question such as 'Do you have pain or discomfort in the throat?' [12]. This question was asked after confirming that the patient mental status was clear. In addition, the degree of sore throat severity was measured using a visual analogue scale (VAS), where 0 indicates no pain and 10 indicates the worst pain imaginable [13]. After this assessment, the patient received a bolus administration of fentanyl $100 \mu \mathrm{g}$ and propacetamol $2 \mathrm{~g}$, followed by an intravenous patient-controlled analgesia (IV-PCA) with fentanyl and propacetamol. IV-PCA with the same regimen was applied until the end of the study ( $48 \mathrm{~h}$ ). If additional rescue analgesia was needed, it was recorded. The severity and incidence of POST were assessed at 1, 6, 24, and $48 \mathrm{~h}$ after tracheal extubation in the same manner. The occurrence of hoarseness, coughing, and any postoperative complication for $48 \mathrm{~h}$ was also assessed.

\section{Statistical analysis}

The sample size calculation for the present study was based on $0 \mathrm{~h}$ VAS scores in a pilot study ( $\mathrm{n}=8$ in each group, total $\mathrm{n}=32$ ). According to the pilot study, we calculated the variance $\left(\sigma^{2}\right)=0.05792114$ (effect size $=0.248$ ). With a power of $80 \%$ at a significance level of 0.05 for one way analysis of variance (ANOVA), a total sample size of 132 was calculated (33 patients for each group). Taking into account potential drop- outs, a total of 144 patients were allocated to 4 groups (36 patients for each group). All statistical analyses were performed with SPSS (SPSS 18.0, IBM Corp., USA). Continuous variables were tested for normal distribution using the KolmogorovSmirnov test. Severity of POST and demographic data (age, weight, height, and body mass index) were analyzed using a one-way ANOVA. Remifentanil dosage, duration of intubation, and tube cuff pressure were analyzed using the nonparametric Kruskal-Wallis test. Chi-square or Fisher's exact test was used for comparing the incidence of POST and other binary/categorical variables. $\mathrm{P}$ values $<0.05$ were considered statistically significant. All results are expressed as the mean \pm standard deviation, median $(1 \mathrm{Q}, 3 \mathrm{Q})$, or numbers (percentage).

\section{RESULTS}

No significant difference was observed in the severity of POST at all time points (Table 3 ).

The incidences of POST at $0,1,6,24,48 \mathrm{~h}$, and 0-48 h (overall) after extubation are presented in Table 4 . The overall incidence of POST was significantly lower in the Combined group (52.9\%) than in the Control group (79.4\%; $\mathrm{P}=0.021)$, Lidocaine group (81.8\%; $\mathrm{P}=0.012)$, and Softened group (82.9\%; $\mathrm{P}=0.010$ ), whereas no significant difference was found among the Control group, Lidocaine group, and Softened group. Similarly, upon arrival at the recovery room $(0 \mathrm{~h})$, the incidence of POST was significantly lower in the Combined group (47.1\%) than in the Control group (76.5\%; $\mathrm{P}=0.013)$, Lidocaine group (78.8\%; $\mathrm{P}=0.007)$, and Softened group (74.3\%; $\mathrm{P}=0.021$ ), whereas no significant difference was found among the Control group, Lidocaine group, and Softened group. From $1 \mathrm{~h}$ after extubation (at 1, 6, 24, and $48 \mathrm{~h}$ ), the incidence of POST was not significantly different among the groups. The overall incidence of hoarseness did

Table 3. Severity of Postoperative Sore Throat after Extubation (Visual Analogue Scale)

\begin{tabular}{|c|c|c|c|c|c|}
\hline Time & Control $(n=34)$ & Lidocaine $(n=33)$ & Softened $(n=35)$ & Combined $(n=34)$ & Pvalue \\
\hline $\mathrm{Oh}$ & $1.8 \pm 1.3$ & $1.9 \pm 1.3$ & $1.7 \pm 1.2$ & $1.3 \pm 1.6$ & 0.217 \\
\hline $1 \mathrm{~h}$ & $1.1 \pm 1.1$ & $1.1 \pm 1.0$ & $1.2 \pm 1.0$ & $0.9 \pm 1.0$ & 0.581 \\
\hline $6 \mathrm{~h}$ & $1.0 \pm 0.2$ & $0.2 \pm 0.9$ & $0.1 \pm 0.5$ & $0.5 \pm 1.1$ & 0.063 \\
\hline $24 \mathrm{~h}$ & $0.2 \pm 0.8$ & $0.1 \pm 0.4$ & $0.1 \pm 0.2$ & $0.1 \pm 0.3$ & 0.375 \\
\hline $48 \mathrm{~h}$ & $0 \pm 0$ & $0 \pm 0$ & $0.0 \pm 0.2$ & $0 \pm 0$ & 0.410 \\
\hline
\end{tabular}

Values are presented as mean \pm SD. Control: un-softened endotracheal tube (ETT) lubricated with saline, Lidocaine: un-softened ETT lubricated with $2 \%$ lidocaine jelly, Softened: thermally softened ETT lubricated with saline, Combined: thermally softened ETT lubricated with $2 \%$ lidocaine jelly. 
Table 4. Incidences of Postoperative Sore Throat after Extubation

\begin{tabular}{|c|c|c|c|c|c|}
\hline Time & Control $(n=34)$ & Lidocaine $(n=33)$ & Softened $(n=35)$ & Combined $(n=34)$ & $P$ value \\
\hline Overall & $27(79.4)^{*}$ & $27(81.8)^{*}$ & $29(82.9)^{*}$ & $18(52.9)$ & 0.012 \\
\hline $\mathrm{Oh}$ & $26(76.5)^{*}$ & $26(78.8)^{*}$ & $26(74.3)^{*}$ & $16(47.1)$ & 0.015 \\
\hline $1 \mathrm{~h}$ & $20(58.8)$ & 19 (57.6) & $22(62.9)$ & $17(50.0)$ & 0.749 \\
\hline $6 \mathrm{~h}$ & $11(32.4)$ & $6(18.2)$ & $3(8.6)$ & $5(14.7)$ & 0.073 \\
\hline $24 \mathrm{~h}$ & $4(11.8)$ & $3(9.1)$ & $4(11.4)$ & $2(5.9)$ & 0.832 \\
\hline $48 \mathrm{~h}$ & $0(0)$ & $0(0)$ & $1(2.9)$ & $0(0)$ & 0.406 \\
\hline
\end{tabular}

Values are presented as number of patients (\%). Control: un-softened endotracheal tube (ETT) lubricated with saline, Lidocaine: un-softened ETT lubricated with $2 \%$ lidocaine jelly, Softened: thermally softened ETT lubricated with saline, Combined: thermally softened ETT lubricated with $2 \%$ lidocaine jelly. *P $<0.05$ compared to Combined group by chi-square test.

not differ among the groups (14.7\% in Control group; $3.0 \%$ in Lidocaine group; $2.9 \%$ in Softened group; $5.8 \%$ in Combined group, $\mathrm{P}=0.071$ ). No other postoperative complications were observed in any of the patients.

\section{DISCUSSION}

POST can be the consequence of mechanical injury during the intubating process and mucosal injury by the cuff pressure, leading to inflammatory changes. To reduce such injuries with less cost and effort, we selected two possible preventive interventions that are safe and easy to apply in clinical settings. The present study demonstrated that the combination of thermally softened ETT and $2 \%$ lidocaine jelly decreased the overall incidence of POST, and this combination especially reduced POST in the immediate postoperative period after extubation. However, the single method of thermally softened ETT or $2 \%$ lidocaine jelly did not prevent POST compared with the control group.

A recent study showed that thermally softened doublelumen endobronchial tube significantly reduced the incidence of POST compared with non-softened tubes [10]. We expected this thermal softening method to help single-lumen ETT pass through the larynx and trachea more smoothly, and can even be molded to the shape of the trachea. However, in the present study, this non-pharmacological intervention was not effective for the single-lumen ETT. This discrepancy might be due to the different stiffnesses and external diameters of the tubes. Because single-lumen tubes are not as stiff as double lumen tubes and have a smaller external diameter, the beneficial effect of thermal softening for the prevention of POST may not be prominent in single-lumen tubes.

Lidocaine jelly (2\%) applied on the tubes as a pharmaco- logical intervention was also not effective in this study. In an earlier study, a comparison between dry tubes and lubricated tubes with $1 \%$ cinchocaine jelly suggested that the use of lubricants containing a local anesthetic may be beneficial for the prevention of POST [14]. However, in other studies $[8,15,16], 2 \%$ lidocaine jelly did not decrease the incidence of POST, which is a similar result as that of the present study. Lee et al. [9] even showed that lidocaine jelly applied on the ETT with tapered-shaped cuff increased the overall incidence of POST compared with the control. They attributed this deleterious effect to potentially irritating additives in lidocaine jelly, such as chlorhexidine gluconate (Instillagel, 2\% jelly, CliniMed Limited, UK), and suggested that a tapered-shaped cuff might enhance this effect by keeping the lidocaine jelly in a greater contact area than the conventional cylindrical cuff. While the same ETT with a tapered-shaped cuff was used in the present study, we used a different lidocaine jelly that has none of the irritating additives previously identified. In view of the results obtained, $2 \%$ lidocaine jelly seems to neither decrease nor increase the incidence of POST when there are no potentially irritating additives.

Neither thermal softening nor $2 \%$ lidocaine jelly were effective when used separately in the present study, although a combination of the two interventions surprisingly resulted in a significantly decreased incidence of POST. The mechanism by which this combination reduces POST is not clear. The possible explanation is that a combination of minor effects from both interventions was revealed to be statistically significant in an additive or synergistic fashion. It is likely that an analgesic effect of $2 \%$ lidocaine jelly and reduced irritant effect of thermally softened tube act together to reduce sore throat. Regardless of the precise mechanism, the result of the present study demonstrates that the overall incidence of 
POST may decrease by applying $2 \%$ lidocaine jelly on thermally softened ETT.

In the present study, the overall incidence was higher than in previous studies in which the incidence was $40-54 \%[1,2,4]$. This higher incidence seems to be related to the measurement time point. While the first measurement of POST in most previous studies was accomplished one or more hours after the operation, we performed the first measurement immediately after arriving at the recovery room. The selection of this time point $(0 \mathrm{~h})$ was made to enable investigation of the effect of preventive interventions before the routine administration of postoperative analgesics. The incidence of POST $1 \mathrm{~h}$ after operation was about $50-63 \%$, which is comparable to that of previous studies.

The present study has several limitations. Firstly, the incidence of POST might be influenced by a fentanyl-propacetamol mixture which has analgesic and anti-inflammatory properties. In the recovery room, these drugs were administered to all patients for postoperative pain control. In fact, the result of this study shows that the initial sore throat symptom of many patients was resolved in one hour after arrival at the recovery room. However, the amount of analgesic administered did not differ among the groups. This could permit a comparison of the effectiveness of different interventions in the present study. Secondly, it was impossible to blind the investigator who performed endotracheal intubation because the difference between room temperature ETTs and thermally softened ETTs was readily apparent, even though the tubes were hidden by opaque bottles until immediately before intubation. In addition, the investigator was able to distinguish between lidocaine jelly and saline. Potential bias was minimized by blinding the investigator who measured postoperative outcomes. Thirdly, we did not record the objective signs of sore throat after surgery, such as the degree of mucosal damage, to reduce health care cost and patients' inconvenience. However, subjective symptoms should be sufficient to assess the incidence and severity of POST because it is a self-limiting inflammatory process with/without minor mucosal erosion in most cases. However, with objective data, we might have been able to suggest a clear hypothesis about the benefit of combined interventions.

In conclusion, no difference was observed in the severity of POST. However, $2 \%$ lidocaine jelly applied on thermally softened single-lumen ETT reduced the overall incidence of
POST. Therefore, this combined intervention could be considered as an alleviating strategy for POST.

\section{CONFLICTS OF INTEREST}

No potential conflict of interest relevant to this article was reported.

\section{ORCID}

Ji-A Song: https://orcid.org/0000-0001-7600-3572

Seongheon Lee: https://orcid.org/0000-0002-2675-2521

Jeong-Il Choi: https://orcid.org/0000-0002-3571-2599

Hyung Gon Lee: https://orcid.org/0000-0003-3058-3748

Sue Youn Park: https://orcid.org/0000-0003-4908-8392

Jeong Yeon Hwang: https://orcid.org/0000-0002-4417-3953

Sanghee Park: https://orcid.org/0000-0003-3743-4024

\section{REFERENCES}

1. Chang JE, Kim H, Han SH, Lee JM, Ji S, Hwang JY. Effect of endotracheal tube cuff shape on postoperative sore throat after endotracheal intubation. Anesth Analg 2017; 125: 1240-5.

2. Biro P, Seifert B, Pasch T. Complaints of sore throat after tracheal intubation: a prospective evaluation. Eur J Anaesthesiol 2005; 22 : 307-11.

3. Christensen AM, Willemoes-Larsen H, Lundby L, Jakobsen KB. Postoperative throat complaints after tracheal intubation. Br J Anaesth 1994; 73: 786-7.

4. Higgins PP, Chung F, Mezei G. Postoperative sore throat after ambulatory surgery. Br J Anaesth 2002; 88: 582-4.

5. Macario A, Weinger M, Carney S, Kim A. Which clinical anesthesia outcomes are important to avoid? The perspective of patients. Anesth Analg 1999; 89: 652-8.

6. Tanaka Y, Nakayama T, Nishimori M, Tsujimura Y, Kawaguchi M, Sato Y. Lidocaine for preventing postoperative sore throat. Cochrane Database Syst Rev 2015; (7): CD004081.

7. Mekhemar NA, El-Agwany AS, Radi WK, El-Hady SM. Comparative study between benzydamine hydrochloride gel, lidocaine $5 \%$ gel and lidocaine $10 \%$ spray on endotracheal tube cuff as regards postoperative sore throat. Braz J Anesthesiol 2016; 66: 242-8.

8. Sumathi PA, Shenoy T, Ambareesha M, Krishna HM. Controlled comparison between betamethasone gel and lidocaine jelly applied over tracheal tube to reduce postoperative sore throat, cough, and hoarseness of voice. Br J Anaesth 2008; 100: 215-8.

9. Lee J, Lee YC, Son JD, Lee JY, Kim HC. The effect of lidocaine jelly 
on a taper-shaped cuff of an endotracheal tube on the postoperative sore throat: a prospective randomized study: a CONSORT compliant article. Medicine (Baltimore) 2017; 96: e8094.

10. Seo JH, Cho CW, Hong DM, Jeon Y, Bahk JH. The effects of thermal softening of double-lumen endobronchial tubes on postoperative sore throat, hoarseness and vocal cord injuries: a prospective double-blind randomized trial. Br J Anaesth 2016; 116: 282-8.

11. Shanahan E, Yu CV, Tang R, Sawka A, Vaghadia H. Thermal softening of polyvinyl chloride nasotracheal tubes: effect of temperature on tube navigability. Can J Anaesth 2017; 64: 331-2.

12. Harding CJ, McVey FK. Interview method affects incidence of postoperative sore throat. Anaesthesia 1987; 42: 1104-7.
13. DeLoach LJ, Higgins MS, Caplan AB, Stiff JL. The visual analog scale in the immediate postoperative period: intrasubject variability and correlation with a numeric scale. Anesth Analg 1998; 86: 102-6.

14. Winkel E, Knudsen J. Effect on the incidence of postoperative sore throat of 1 percent cinchocaine jelly for endotracheal intubation. Anesth Analg 1971; 50: 92-4.

15. Basaranoglu G, Erden V, Delatioglu H. Postoperative sore throat: effect of lidocaine jelly and pomade on endotracheal intubation. J Clin Anesth 2004; 16: 79-80.

16. Soltani HA, Aghadavoudi O. The effect of different lidocaine application methods on postoperative cough and sore throat. J Clin Anesth 2002; 14: 15-8. 